University of Nebraska - Lincoln

DigitalCommons@University of Nebraska - Lincoln

\title{
Effect of Age and Mating Status on Adult European Corn Borer (Lepidoptera: Crambidae) Dispersal from Small-Grain Aggregation
} Plots

\author{
Brendon J. Reardon \\ lowa State University \\ Thomas W. Sappington \\ USDA-ARS, tsapping@iastate.edu
}

Follow this and additional works at: https://digitalcommons.unl.edu/usdaarsfacpub

Part of the Agricultural Science Commons

Reardon, Brendon J. and Sappington, Thomas W., "Effect of Age and Mating Status on Adult European Corn Borer (Lepidoptera: Crambidae) Dispersal from Small-Grain Aggregation Plots" (2007). Publications from USDA-ARS / UNL Faculty. 734.

https://digitalcommons.unl.edu/usdaarsfacpub/734

This Article is brought to you for free and open access by the U.S. Department of Agriculture: Agricultural Research Service, Lincoln, Nebraska at DigitalCommons@University of Nebraska - Lincoln. It has been accepted for inclusion in Publications from USDA-ARS / UNL Faculty by an authorized administrator of DigitalCommons@University of Nebraska - Lincoln. 


\title{
Effect of Age and Mating Status on Adult European Corn Borer (Lepidoptera: Crambidae) Dispersal from Small-Grain Aggregation Plots
}

\author{
BRENDON J. REARDON ${ }^{1}$ AND THOMAS W. SAPPINGTON ${ }^{2}$ \\ USDA-ARS Corn Insects and Crop Genetics Research Unit, Genetics Laboratory, Iowa State University, Ames, IA 50011
}

J. Econ. Entomol. 100(4): 1116-1123 (2007)

\begin{abstract}
The European corn borer, Ostrinia nubilalis (Hübner) (Lepidoptera: Crambidae), is often controlled with genetically modified corn, Zea mays L., hybrids (Bacillus thuringiensis [Bt] corn) in the United States. If Bt-resistant insects are detected in the field, mitigation-remediation tactics must be implemented to sustain the efficacy of insecticidal, transgenic corn. Mass releasing laboratoryreared, susceptible adults near aggregation sites to mate with locally emerging resistant adults is a possible remediation tactic, but it is imperative that the former remain in or near the release site long enough to mate. Understanding adult dispersal behavior relative to the timing of mating is important, because it directly affects patterns of gene flow and the rate at which Bt resistance moves through a population. Previous work shows that newly eclosed adults do not remain in proximity to their natal field. However, moth age, reproductive development, or mating status may influence the propensity to disperse. The objectives of this study were to determine the effect of adult age $(0-3,4-6$, and 7-10 $\mathrm{d}$ old) and mating status on dispersal of adults released in small-grain aggregation plots. Less than $1 \%$ of the marked adults released in the aggregation plots remained after one night. More males than females were recovered. Age influenced dispersal, with mostly 4-6-d old adults being recovered. Conversely, mating status did not affect the number of adults recovered. Given the paucity of marked adult moths recovered near their release sites, mass releases of adults may not be a viable tactic to combat the spread of resistance to Bt corn.
\end{abstract}

KEY WORDS European corn borer, Ostrinia nubilalis, dispersal, Bt, transgenic corn

The production of corn, Zea mays L., in most of North America east of the Rocky Mountains is vulnerable to the European corn borer, Ostrinia nubilalis (Hübner) (Lepidoptera: Crambidae). Control costs and reductions in corn yield associated with $O$. nubilalis in the United States have exceeded $\$ 1$ billion annually (Mason et al. 1996). Since 1996, commercial availability of genetically modified corn hybrids that express insecticidal genes from Bacillus thuringiensis Berliner (Bt) for the control of $O$. nubilalis has increased corn yields and improved pest control (Koziel et al. 1993, Pilcher et al. 2002). However, O. nubilalis may develop resistance to Bt corn, reducing the efficacy of this transgenic technology (Chaufaux et al. 2001, Bates et al. 2005, Alves et al. 2006).

If resistance to $\mathrm{Bt}$ corn becomes evident in an $O$. nubilalis population, manipulation of the spatial distribution of susceptible and resistant adults to promote interbreeding may reduce the frequency of resistance

This article reports the results of research only. Mention of a proprietary product does not constitute an endorsement or a recommendation by the USDA for its use.

${ }^{1}$ Current address: USDA-APHIS PPQ, 350 Corporate Boulevard, Robbinsville, NJ 08691.

${ }^{2}$ Corresponding author, e-mail: Tom.Sappington@ars.usda.gov. alleles and slow the spread of resistance (Alstad and Andow 1995, Andow and Ives 2002). Provision or removal of aggregation sites may be one such method for adult manipulation (Showers et al. 1980, Derrick and Showers 1991, Hellmich et al. 1998). Caffrey and Worthley (1927) first reported that O. nubilalis adults are found in dense vegetation outside agricultural crops during the day. Although $O$. nubilalis adults may occupy irrigated cornfields in the western Corn Belt (Hunt et al. 2001, Qureshi et al. 2005), they usually colonize areas of dense grass in or bordering rain-fed cornfields in the Midwest (Showers et al. 1976, DeRozari et al. 1977) and Europe (Bontemps et al. 2004, Dalecky et al. 2006). These aggregation sites are where mating behaviors usually occur, including emission of female sex pheromone and copulation (Klun 1968, DeRozari et al. 1977, Sappington and Showers 1983a).

For mass releases of Bt-susceptible O. nubilalis to work on a local, field scale as a resistance mitigation strategy, it may be important that susceptible adults remain in the vicinity of Bt-resistant adults long enough to mate with one another. Reardon et al. (2006) explored the possibility of mass releasing laboratory-reared, susceptible $O$. nubilalis via placing 
rings of pupae in a cornfield in proximity to small-grain aggregation plots provided for colonization. They concluded that this may not be a viable remediation tactic, because almost all $(>99 \%)$ of the newly emerged adults dispersed on the first night beyond the grassy aggregation sites provided in the immediate vicinity of the release point (i.e., $\geq 300 \mathrm{~m}$ ). Similarly, Dalecky et al. (2006) found in mark-release experiments in France that the proportion of adults $<1 \mathrm{~d}$ old dispersing beyond the adjacent grassy field edge from their release site $7 \mathrm{~m}$ distant in corn was high, but variable. Their recapture rate from the grass at $36 \mathrm{~h}$ postrelease (i.e., after two nights) ranged from 0.2 to $26.9 \%$, averaged $4.3 \pm 1.6 \%$ (SE), and had medians of $1.8 \%$ for both males and females. Showers et al. (1976) found that, when released as 1-d-old adults, O. nubilalis dispersed from small plots of grass and corn within $\approx 1 \mathrm{~d}$. Showers et al. (2001) noted that only a small proportion of newly emerged moths released in open fields could be found in grassy areas $<200 \mathrm{~m}$ from the release point, and most dispersed $>800 \mathrm{~m}$ within 1-2 d. However, age and reproductive development of adult Lepidoptera often influence dispersal behavior (Johnson 1969), including probably that of O. nubilalis (XiangQuan et al. 2004), so releasing adults of appropriate developmental status may improve retention of susceptible adults in release areas.

In this study, we provided potential aggregation sites to O. nubilalis adults by planting dense plots of small grains. The species of small grains used, and the dates and rates at which the plots were planted, were found in previous studies to provide appropriate habitat for adult $O$. nubilalis aggregation (Hellmich et al. 1998, Anderson et al. 2003, Reardon et al. 2006). Our goal was to determine whether we could create a combination of extrinsic and intrinsic conditions suitable to retain laboratory-reared $O$. nubilalis near their site of release when taken to the field as adults. Success would provide the rationale for developing a mitigation plan based on introducing large numbers of Btsusceptible adults to an area where resistance alleles are increasing in frequency in a population. The objectives of this study were to determine the effect of adult age and mating status on dispersal of laboratoryreared $O$. nubilalis adults from small-grain aggregation plots.

\section{Materials and Methods}

Insect Culture. Laboratory colonies of $O$. nubilalis are established annually at the USDA-ARS Corn Insects and Crop Genetics Research Unit, Ames, IA. Adults collected from light traps in Story County, IA, in 2004 were used to initiate colonies that were the source of marked insects used in the experiments in 2005. Larvae were reared on meridic diet of wheat germ using standard procedures (Raun 1961, Guthrie et al. 1965, Lewis and Lynch 1969). The larvae fed $\approx 21$ $\mathrm{d}$ on diet impregnated with either Solvent Blue 35 (Sudan Blue II, C.I. 306436; Sigma-Aldrich, Milwaukee, WI), which stained the fat bodies of the larvae blue, or Fat Red 7B (Sudan Red 7B, C.I. 201618), which stained the fat bodies red. The mark was retained through adulthood. Ostlie et al. (1984) and Hunt et al. (2000) reported that these two dyes were not deleterious to the moths and that they had negligible effects on their biology. Each dish containing the diet and larvae was overlaid with a ring of corrugated cardboard that larvae colonized for pupation. Larvae were reared in an environmentally controlled room at $27^{\circ} \mathrm{C}, 80 \% \mathrm{RH}$, and a photoperiod of $16: 8$ (L:D) $\mathrm{h}$ through pupation. Each ring contained 600-800 pupae, with a presumed sex ratio of $\approx 1: 1$ (Guthrie et al. 1985).

To test the effect of age on dispersal behavior, four rings of pupae were suspended per 61- by 61 - by $61-\mathrm{cm}$ wire-mesh cage held in an environmentally controlled room at $27^{\circ} \mathrm{C}, 80 \% \mathrm{RH}$, and a photoperiod of $16: 8$ (L:D) h. Marked adults emerging from the rings were held in cages to create cohorts of $0-3,4-6$, or $7-10 \mathrm{~d}$ old adults. Cages were provisioned daily with watersoaked cotton. Two cages of differently aged adults were released weekly per location, with the two age classes of adults differing by color. The number of pupae per ring was estimated for each release by counting all pupae in two rings for each color. After a release, the number of empty pupal cases in two rings per color per location was used to estimate the number of adults of each color released.

To test the effect of mating status of adults on dispersal behavior, rings of pupae were suspended in cages, and adults were allowed to emerge and mate for $3 \mathrm{~d}$ before the rings were removed, and the cages were taken to the field for release. To release unmated adults, we removed pupae from rings, and determined the sex based on the morphology of the pupal case. Four hundred fifty to 750 pupae of each sex were placed separately on trays in cages, and they were furnished with water-soaked cotton in an environmentally controlled room at $27^{\circ} \mathrm{C}, 80 \% \mathrm{RH}$, and a photoperiod of 16:8 (L:D) h for $3 \mathrm{~d}$ before release in the field. The unmated and mated adults differed by color. Because males and females were held separately to prevent mating, and another cage of mixed sexes was used to allow copulation, three cages were brought to each location per release. To confirm that females in the "mated" treatment group had indeed mated successfully, 10 females per mating cage were dissected the day of release to determine their status by the presence or absence of a spermatophore (Showers et al. 1974).

Experimental Design. O. nubilalis is bivoltine in much of the Corn Belt, including Iowa (Mason et al. 1996). The first flight begins usually in mid-May, and the second flight in mid-July. Each flight lasts typically $3-6 \mathrm{wk}$, but the second flight is generally longer than the first flight. For each flight, seven locations next to cornfields were planted to small grains in Story and Boone counties, IA, to create aggregation sites for $O$. nubilalis. Each location was $\approx 0.4 \mathrm{ha}$, and it was split into six to 1210 - by $30-\mathrm{m}$ plots. Half of the plots were planted to 'Jerry' oats, Avena sativa (L.), at twice the standard density $(180 \mathrm{~kg} / \mathrm{ha})$ to attract adults over the first flight (Hellmich et al. 1998, Reardon et al. 2006). 
The oat plots were planted sequentially at each location between 4 April and 2 May at $\approx 1$-wk intervals to ensure the presence of at least one plot on a given release date with a phenology suitable for adult aggregation. The remaining plots were planted to 'Manta' Siberian foxtail hay millet, Setaria italica L., at twice the standard density $(45 \mathrm{~kg} / \mathrm{ha})$ to attract adults during the second flight (Anderson et al. 2003, Reardon et al. 2006). The millet plots were planted sequentially at each location between 26 May and 16 June at $\approx 1$-wk intervals. Thus, there were about six planting dates per adult flight. Releases of marked adults were conducted weekly. For a given release, cages of marked adults were placed in plots that were most acceptable phenologically for aggregation based on visual appearance of the grass (DeRozari et al. 1977) and the presence of feral adults. Cages were placed in the field in the late afternoon, and they were removed from plots the next morning. Cages had a 20by $58-\mathrm{cm}$ opening on the top of the side to allow emergence of marked adults. The next day when cages were removed from each location, the number of adults remaining in each cage was counted to adjust the calculation of number of marked adults released. Eight releases per location were made between 9 June and 6 August during either the first or second flights of feral adults. Differently aged adults were released at four locations, and adults of different mating status were released in the remaining three locations.

Data Collection. Each location was sampled before 0900 the day of adult release (i.e., a prerelease sample) and each day following for $3 \mathrm{~d}$. During a flight, each plot at each location (oat plots during first flight, millet plots during second flight) was swept 30 times using a heavy-duty, 0.38-m-diameter sweep net (Bioquip Products, Inc., Rancho Dominguez, CA). The origin (red, blue, or feral), sex, and mating status of females based on the presence and melanization of the spermatophore were determined (Showers et al. 1974). We also used a flush-bar technique to increase the area of plots sampled at a location and to facilitate the determination of suitability of the plots as aggregation sites (Sappington and Showers 1983b, Derrick and Showers 1990, Reardon et al. 2006). A 1.5-m plastic rod was used to disturb grass along a 30 -m edge of two sides of each plot (i.e., $60 \mathrm{~m}$ total per plot) at each location. Adults were counted visually on the wing as they fluttered up from the plot being sampled (Sappington and Showers 1983b). Only plots at locations where at least one feral adult moth was recovered during a release were used in the analyses. If at least one feral adult moth was collected with the sweep net during a given release in a plot, then all data from that particular plot during that release were included in the analyses. Similarly, if at least one adult was flushed from a plot the day before the release, then all data from that plot during that release were included in the analyses.

Statistical Analyses. The number of marked adults of each color that was released per week was estimated as the product of the number of pupae per cage and the estimated proportion of emergence. The expected number of marked adults to be recovered per plot per location was calculated under the scenario that all of the marked adults released occupied only the acceptable plots corresponding to a given flight (oats or millet) and that they were distributed uniformly within them at that location. Thus, the expected mean number of released adults occupying each plot was calculated by dividing the number of marked adults of a given color released at a location by the number of suitable plots at that location (based on the presence of feral adults) for a given release. That quotient was multiplied by the fraction of area of a plot that was sampled with the sweep net on a given sample date to calculate the number of marked adults expected to be recovered by the sweep net per plot per location per release. Proportion of a plot that was swept on a sample date (0.038) was calculated as the product of sweeps per plot $(30)$, net rim diameter $(0.38 \mathrm{~m})$ that was swung $\approx 1 \mathrm{~m}$ per sweep, and the inverse of the plot area $\left[\left(300 \mathrm{~m}^{2}\right)^{-1}\right]$.

An analysis of variance (ANOVA) (restricted maximum likelihood estimates; REML-ANOVA) was used for all analyses of means, using mixed models (PROC MIXED, SAS Institute 2001). To determine whether the observed mean number of marked adults collected with the sweep net was different from the mean number of marked adults expected to be recovered if all remained in the acceptable plots, the fixed effect of the mixed model was moth category (expected, observed). We determined whether the mean number of males recovered was different from the mean number of females recovered, using sex as the fixed effect. The age and mating status data were tested separately. We determined whether age influenced the number of adults recovered, and the fixed effect was age class. We also determined whether mating status influenced the number of adults recovered, and the fixed effect was mating status. The dependent variable in all models was the mean number of marked adults swept per plot. Parameter means were separated using the LSMEANS option of PROC MIXED (SAS Institute 2001). The random effects in all models were location, days after release nested in release, and crop (oats, millet).

All dependent data were transformed to $\ln (\overline{\mathrm{X}}+$ 0.5 ) to meet the assumptions of homoscedasticity and normality (Ott and Longnecker 2001). Assumptions were assessed with residual and normal plots (PROC UNIVARIATE, SAS Institute 2001).

\section{Results}

In total, 46 feral moths were collected with the sweep net from the aggregation plots over the seven locations over the eight releases of marked adults, and 50 adults were flushed the day before releases. Presuming that all adults in plots the day before a release were feral, the flush data supplement the sweep data, and together they suggest that at least some of the plots at each location on each release date were suitable as aggregation sites. 
Table 1. Expected and observed mean number of marked $O$. nubilalis adults recovered from aggregation plots with a sweep net within $3 \mathrm{~d}$ of release in age (all ages pooled) and mating status (mated and unmated pooled) experiments

\begin{tabular}{|c|c|c|c|c|}
\hline Exp & Release $^{a}$ & Release date & $\begin{array}{l}\text { Expected } \bar{x}(\mathrm{SE}) \text { per } \\
\text { aggregation plot }\end{array}$ & $\begin{array}{c}\text { Observed } \bar{x}(\mathrm{SE}) \text { per } \\
\text { aggregation plot }\end{array}$ \\
\hline \multirow[t]{4}{*}{ Age } & 1 & 3 June & $124.34(5.19)$ & $0.06(0.06)$ \\
\hline & 2 & 9 June & $54.78(1.77)$ & $0.18(0.07)$ \\
\hline & 3 & 16 June & $35.65(1.51)$ & $0.00(0.00)$ \\
\hline & 4 & 30 July & $138.72(0.00)$ & $0.50(0.50)$ \\
\hline \multirow[t]{4}{*}{ Mating status } & 1 & 5 June & $104.33(9.93)$ & $0.50(0.42)$ \\
\hline & 2 & 13 June & $49.33(2.79)$ & $0.38(0.13)$ \\
\hline & 3 & 27 July & $113.5(25.50)$ & $5.00(1.00)$ \\
\hline & 4 & 8 Aug. & $82.00(0.00)$ & $0.00(0.00)$ \\
\hline
\end{tabular}

${ }^{a}$ For the age experiment, 44,900 marked adults were released, and for the mating status experiment, 14,545 marked adults were released

${ }^{b}$ The expected number if all released adults colonized suitable aggregation plots at the release location, based on the amount of area sampled by the sweep net.

In both the age and the mating status experiments, fewer marked adults than expected were recovered from aggregation plots during every release (Table 1). The REML-ANOVA models applied to both the age data $(F=4493.23$; $\mathrm{df}=1,81.8 ; P<0.0001)$ and the mating-status data $(F=1083.88$; df $=1,41.9 ; P<$ $0.0001)$ indicate that the expected and observed mean number of adults recovered were significantly different. The least-squares means of the expected and observed mean number of marked adults recovered were significantly different for the age $(t=67.03$; $\mathrm{df}=1$, 81.8; $P<0.0001)$ and mating status experiments $(t=$ 32.92; df $=1,41.9 ; P<0.0001)$. In both the age and mating status experiments, no marked adults were ever recovered before a release, and few to no marked adults were recovered by $3 \mathrm{~d}$ after a release (Fig. 1).

Sex did not significantly influence the number of marked adults recovered from aggregation plots in the age experiment $(F=1.88 ; \mathrm{df}=1,79.5 ; P=0.1741)$ (Fig. 2). Among the marked adults recovered, six were male and three were female, where all females were mated and represented each of the mating classes delineated by Showers et al. (1974). More males than

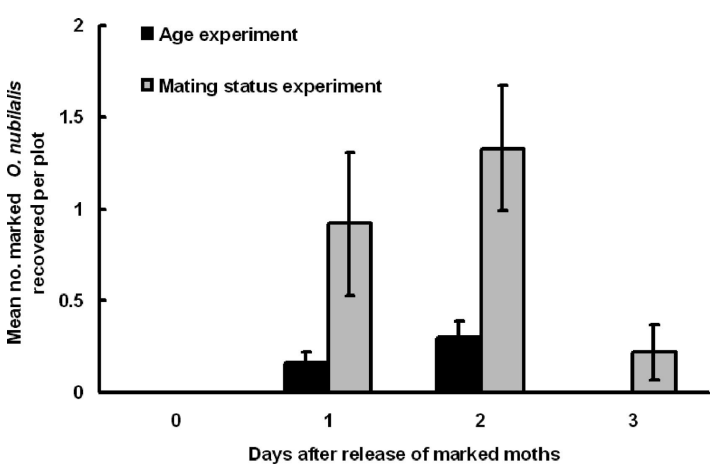

Fig. 1. Mean \pm SE number of marked O. nubilalis moths recovered with a sweep net from aggregation plots of small grains at different times after release in age (all ages pooled) and mating status (mated and unmated pooled) experiments. Day 0 indicates results of sampling on the morning before a release made later in the afternoon. For the age experiment, 44,900 marked adults were released, and for the mating status experiment, 14,545 marked adults were released. females were collected among the feral adults (16 males, 12 females), but the means were not significantly different $(F=1.31 ; \mathrm{df}=1,75.6 ; P=0.2560)$. Greater than $91 \%$ of the feral females had mated within $24 \mathrm{~h}$ of collection (Showers et al. 1974).

Sex significantly influenced the mean number of marked adults recovered in the mating status experiment $(F=5.01$; $\mathrm{df}=1,42.9 ; P=0.0305)$ (Fig. 2). Specifically, significantly more males than females were recovered from the aggregation plots $(t=-2.24$; $\mathrm{df}=1,42.9 ; P=0.0305)$. Twenty-one marked males and four females were recovered. Two of the marked females recovered were unmated when released, but both had mated after release within 24-48 h of recovery with the sweep net (Showers et al. 1974). Of the 18 feral adults collected in the mating status experiment, 16 were male and two were female. Means between the groups were significantly different $(F=$ 5.66; $\mathrm{df}=1,53.0 ; P=0.0210)$, and more males than females were collected $(t=-2.38 ; \mathrm{df}=1,53.0 ; P=$ $0.0210)$.

Despite the paucity of marked adults recovered within $3 \mathrm{~d}$ of their release $(<1 \%)$, we examined the

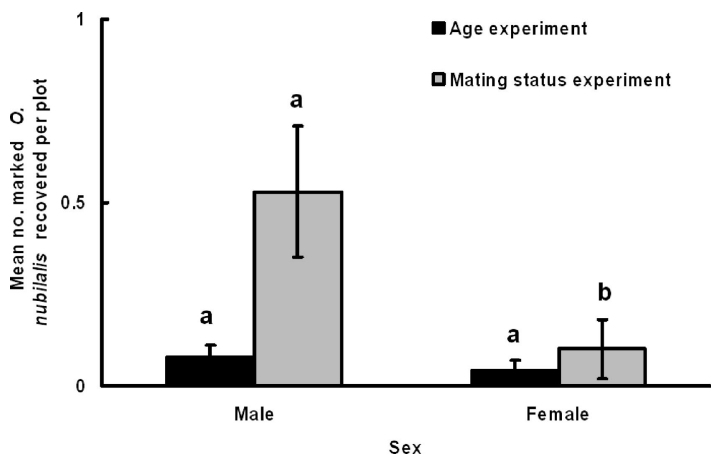

Fig. 2. Mean \pm SE number of marked male and female O. nubilalis adults recovered with a sweep net from aggregation plots of small grains within $3 \mathrm{~d}$ of release in age (all ages pooled) and mating status (mated and unmated pooled) experiments. For the age experiment, 44,900 marked adults were released, and for the mating status experiment, 14,545 marked adults were released. Means corresponding to an experiment with different letters were significantly different based on least-squares differences of means $(P<0.05)$. 


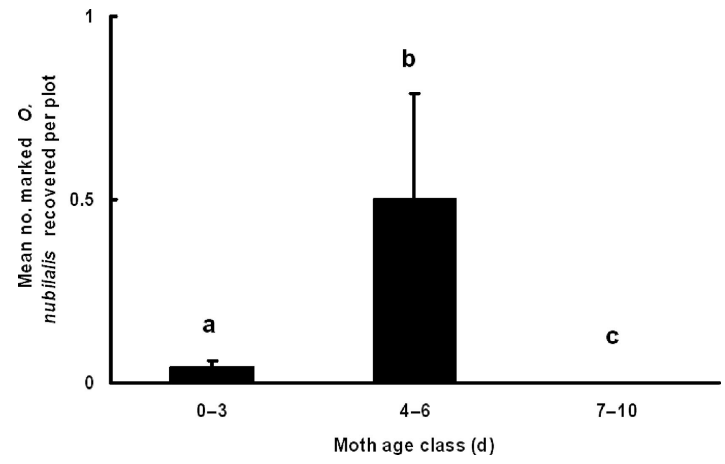

Fig. 3. Mean \pm SE number of marked $O$. nubilalis adults of different age classes recovered with a sweep net from aggregation plots of small grains within $3 \mathrm{~d}$ of release. Adults were held in cages of mixed sexes, so mating status was not controlled and most were mated probably when released; 44 , 900 marked adults were released. Means with different letters were significantly different based on least-squares differences of means $(P<0.05)$.

differences among the age and mating status treatments. The REML-ANOVA model used to examine means of marked adults recovered among the age classes was significant $(F=10.41 ; \mathrm{df}=1,46.5 ; P=$ 0.0023 ) (Fig. 3). Although marked adults in the 7-10 $\mathrm{d}$ age category were never recovered from the aggregation plots (Fig. 3), the least-squares means between the remaining two age classes were significantly different $(t=-3.23 ; \mathrm{df}=1,46.5 ; P=0.0023)$, with more $4-6$-d old adults recovered from aggregation plots than $0-3$-d old adults.

Conversely, the REML-ANOVA model applied to the marked adults recovered in the mating status experiment indicated there was no significant difference in recovery rates between the mated and unmated groups of marked adults released in aggregation plots $(F=3.28 ; \mathrm{df}=1,39.0 ; P=0.0777)$ (Fig. 4). When a similar model was applied to the male-only data, no significant differences in the recovery rates between the mating status groups was found $(F=1.94 ; \mathrm{df}=1$, 39.0; $P=0.1715)$. Too few females $(n=4)$ were

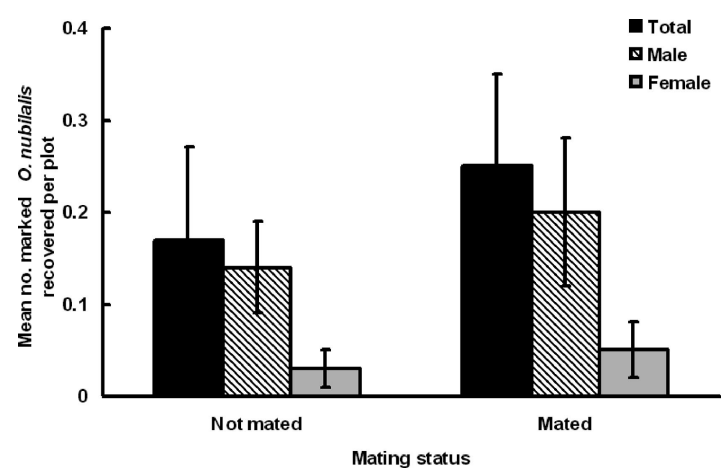

Fig. 4. Mean \pm SE number of mated and unmated, marked $O$. nubilalis adults recovered with a sweep net from aggregation plots of small grains within $3 \mathrm{~d}$ of release; 14,545 marked adults were released. recovered to conduct a test. The range in proportions of females that mated in the mated group was $0.5-0.9$ over the releases with a mean of 0.7 .

\section{Discussion}

The current insect resistance management (IRM) plan for O. nubilalis on Bt corn is predicated on the presumption that a significant proportion of premating dispersal $\geq 800 \mathrm{~m}$ (maximum refuge distance) occurs and thus will reduce the rate of resistance evolution. However, for mass releases to be efficacious in an IRM mitigation context, released susceptible adults should mate with feral resistant adults emerging from Bt fields, or with heterozygotes in an area where the frequency of a Bt resistance allele is increasing in the population. The longer that released $O$. nubilalis adults remain in proximity to the target feral population, the higher the likelihood they will intermate, fostering panmixis. Reardon et al. (2006) found that almost all newly eclosed adults emerging from pupal rings placed in a cornfield dispersed the first night without colonizing adjacent aggregation plots-at least out to $300 \mathrm{~m}$ of the release point. In this study, we attempted to increase the time over which laboratoryreared $O$. nubilalis remain near their point of release by manipulating age and mating status, and by directly releasing the adults in suitable aggregation habitat. Despite their apparent suitability as aggregation sites, manyfold fewer marked adults than expected remained in the plots of small grains, regardless of age or mating status (Table 1). Very few adults were recovered at the release site the morning after release, and by $3 \mathrm{~d}$ after release, all marked adults were absent from the aggregation sites.

Premating dispersal of both mass-released and native adults reduces the likelihood of intermating, because spatial overlap between the two populations decreases as dispersal distance increases, and temporal overlap decreases as time of residency at the release site or near the natal field decreases. Thus, our finding that almost all of the marked adults dispersed from the release area the first night argues against the utility of mass releases for resistance mitigation on a local, field scale. However, if a significant proportion of mating occurs the first night of release followed by dispersal the same night, then mass releases still could serve their purpose in a mitigation context.

Two pivotal issues remain unclear regarding $O . n u-$ bilalis dispersal as it relates to resistance mitigation for Bt corn, and IRM in general. The first issue is the distribution of dispersal distances from the natal field expected for a cohort of adults over a given time. Surveys of first-flight $O$. nubilalis distributions among grassy ditches in central Iowa suggest that although some adults may colonize the grass adjacent to their presumed natal cornfields, they do not remain there long (Sappington 2005). Evidence is accumulating that suggests the propensity of $O$. nubilalis to disperse is significant and that most adults may disperse from their natal field with only a few remaining nearby for >1-2 d (Showers et al. 1976, 2001; Hunt et al. 2001, 
Qureshi et al. 2005, Sappington 2005, Dalecky et al. 2006, Reardon et al. 2006). This does not preclude necessarily the utility of mass releases if dispersal distance is not too great, but adequate knowledge of this critical aspect of $O$. nubilalis behavior remains elusive.

Although only a few adults remained near their point of release in the current study, differences observed among their age classes may reflect differential flight behavior corresponding to sexual maturation (Johnson 1969). Teneral males eclose from the pupal case with a near full complement of sperm, and they are able to mate soon after emergence (Chaudhury and Raun 1966). Even though most females are mated by the second night after emergence in the laboratory (Royer and McNeil 1993; B.J.R. and T.W.S., unpublished data), they have about a 3-d preoviposition period (Royer and McNeil 1993, XiangQuan et al. 2004). Dispersal phases of female insects are often timed to occur during the preoviposition period (Johnson 1969, McNeil et al. 1995). Most of the adults recovered in our age experiment were in the 4-6-d age class, the period most likely corresponding to the onset of oviposition (XiangQuan et al. 2004). In our previous study (Reardon et al. 2006), newly emerged marked adults did not colonize nearby aggregation sites, but they dispersed beyond the limits of the experimental arena, and we suggested the possibility that $O$. nubilalis has an obligatory dispersal phase. In addition, our current results indicate that there is a high propensity to disperse from aggregation sites regardless of age.

The second issue regarding $O$. nubilalis dispersal, which is related to the first issue, is where males and females mate relative to the natal field, a problem of paramount importance for IRM (Gould 1998, Showers et al. 2001, Dalecky et al. 2006). Showers et al. (1976, 1980 ) proposed that males spend less time in cornfields than females and that mated gravid females leave aggregation sites soon after copulation to oviposit. Males move nightly among aggregation sites to seek mates (DeRozari et al. 1977, Sappington and Showers 1983a), but it is not clear how far they move. Of those adults released in this study that were recovered, we found generally that more marked males than females remained in aggregation sites, even though we released approximately equal numbers of each sex (Fig. 2 ). This was also true with feral adults collected with the sweep net in aggregation plots. The difference between the sexes was not significant in the age experiment, although numerically more males than females were recovered (Fig. 2). However, significantly more marked males than females were recovered in the mating status experiment, as well as more feral males than feral females (Fig. 2). The proportion of released adults that mated before dispersing on the first night is not known, but of the few marked females recovered at the release site on following days, all were mated. Reardon et al. (2006) also found that $\approx 77 \%$ of the marked females recovered from aggregation sites had mated within $5 \mathrm{~d}$ of release as pupae from a nearby cornfield.
In an experiment in France, Dalecky et al. (2006) found that $\approx 18 \%$ of females $<24$ h old and placed on corn stalks at dusk were mated by the next morning and recovered within $50 \mathrm{~m}$ of their placement site. In another experiment, of the $4 \%$ of marked adults recaptured in grass $36 \mathrm{~h}$ after they had been released just inside the adjacent cornfield, $97 \%$ of the females were mated, and $\approx 19 \%$ of them had mated with released males as indicated by marked spermatophores. They also found that $96 \%$ of the feral females captured in the grass at the previously cleared release sites had mated with wild males, and they suggested that this supports the idea that these wild females had mated near their natal field before dispersal. This interpretation assumes that the adults are limited to a single dispersal flight during their lifetime. However, O. nubilalis adults vacate the grassy aggregation sites each night at dusk in search of free water and oviposition sites (Showers et al. 1976, DeRozari et al. 1977, Sappington and Showers 1983a), and it is unknown whether adults recolonizing the grass later in the night for mating activity or for daytime resting are returning to the same grassy sites they evacuated a few hours earlier. Thus, there may be substantial spatial reshuffling of individuals among grassy sites on a nightly basis before and/or after mating. Nightly reshuffling is suggested by rapid recolonization of natural aggregation sites after removal of resident adults (Showers et al. 1980, Derrick and Showers 1991, Dalecky et al. 2006), but definitive data are lacking. Clearly, O. nubilalis flight behavior in temporal and spatial relation to events such as mating and oviposition is complex, and more research is needed to resolve many of these issues.

The potential use of mass releases, and the ability to modulate dispersal behavior, will require more examination before it can be recommended or dismissed as a potential mitigation-remediation tactic to reduce resistance in $O$. nubilalis populations to Bt corn. Determining the timing and typical geographic extent of dispersal for this species continues to be a major challenge. To help address these questions, we are currently employing molecular markers to estimate gene flow by using population genetics techniques. In addition, flight mill experiments are underway to characterize flight behavior relative to age, sex, and mating status. With this variety of approaches, along with recent and ongoing findings by our colleagues in other laboratories, it is hoped that a coherent picture of $O$. nubilalis dispersal behavior will soon emerge.

\section{Acknowledgments}

We are grateful for field assistance received from E. Berry, M. Dilks, R. Ritland, M. Fiscus, and D. Starret. Furthermore, we are indebted to J. Dyer for assistance in the laboratory.

\section{References Cited}

Alstad, D. N., and D. A. Andow. 1995. Managing the evolution of insect resistance to transgenic plants. Science (Wash., D.C.) 268: 1894-1896. 
Anderson, P. L., M. J. Weiss, R. L. Hellmich, M. P. Hoffmann, and M. G. Wright. 2003. Millet preference, effects of planting date on infestation, and adult and larval use of proso millet by Ostrinia nubilalis (Lepidoptera: Crambidae). J. Econ. Entomol. 96: 361-369.

Alves, A. P., T. A. Spencer, B. E. Tabashnik, and B. D. Siegfried. 2006. Inheritance of resistance to the CrylAb $B a$ cillus thuringiensis toxin in Ostrinia nubilalis (Lepidoptera: Crambidae). J. Econ. Entomol. 99: 494-501.

Andow, D. A., and A. R. Ives. 2002. Monitoring and adaptive resistance management. Ecol. Appl. 12: 1378-1390.

Bates, S. L., J.-Z. Zhao, R. T. Roush, and A. M. Shelton. 2005. Insect resistance management in GM crops: past, present, and future. Nat. Biotechnol. 23: 57-62.

Bontemps, A., D. Bourguet, L. Pélozuelo, M. T. Bethenod, and S. Ponsard. 2004. Managing the evolution of Bacillus thuringiensis resistance in natural populations of the European corn borer, Ostrinia nubilalis: host plant, host race and pherotype of adult males at aggregation sites. Proc. R. Soc. Lond. B 271: 2179-2185.

Caffrey, D. J., and L. H. Worthley. 1927. A progress report on the investigations of the European corn borer. U.S. Dep. Agric. Bull. 1476.

Chaudhury, M.F.B., and E. S. Raun. 1966. Spermatogenesis and testicular development of the European corn borer, Ostrinia nubilalis (Lepidoptera: Pyraustidae). Ann. Entomol. Soc. Am. 59: 1157-1159.

Chaufaux, J., M. Seguin, J. J. Swanson, D. Bourguet, and B. D. Siegfried. 2001. Chronic exposure of the European corn borer (Lepidoptera: Crambidae) to Cry1Ab Bacillus thuringiensis toxin. J. Econ. Entomol. 94: 1-7.

Dalecky, A., S. Ponsard, R. I. Bailey, C. Pélissier, and D. Bourguet. 2006. Resistance evolution to Bt crops: predispersal mating of European corn borers. PloS Biol. 4: 1048-1057.

Derrick, M. E., and W. B. Showers. 1990. Relationship of adult European corn borer (Lepidoptera: Pyralidae) in action sites with egg masses in the cornfield. Environ. Entomol. 19: 1081-1085.

Derrick, M. E., and W. B. Showers. 1991. Comparison of an adult and larval control strategy for the European corn borer (Lepidoptera: Pyralidae) in seed corn. J. Kans. Entomol. Soc. 62: 185-192.

DeRozari, M. B., W. B. Showers, and R. H. Shaw. 1977. Environment and the sexual activity of the European corn borer. Environ. Entomol. 6: 657-665.

Gould, F. 1998. Sustainability of transgenic insecticidal cultivars: integrating pest genetics and ecology. Annu. Rev. Entomol. 43: 701-726.

Guthrie, W. D., E. S. Raun, F. F. Dicke, G. R. Pesho, and S. W. Carter. 1965. Laboratory production of European corn borer egg masses. Iowa State J. Sci. 40: 65-83.

Guthrie, W. D., J. C. Robbins, and J. L. Jarvis. 1985. Ostrinia nubilalis. Iowa Agriculture and Home Economics Experiment Station J-10503: 407-413.

Hellmich, R. L., R. L. Pingel, and W. R. Hansen. 1998. Influencing European corn borer (Lepidoptera: Crambidae) aggregation sites in small grain crops. Environ. Entomol. 27: 253-259.

Hunt, T. E., R. L. Hellmich, J. M. Dyer, L. G. Higley, and J. F. Witkowski. 2000. Oil-soluble dyes for marking European corn borer (Lepidoptera: Crambidae). J. Entomol. Sci. 35: 338-341.

Hunt, T. E., L. G. Higley, J. F. Witkowski, L. J. Young, and R. L. Hellmich. 2001. Dispersal of adult European corn borer within and proximal to irrigated and non-irrigated corn. J. Econ. Entomol. 94: 1369-1377.
Johnson, C. G. 1969. Migration and dispersal of insects by flight. Methuen, London, United Kingdom.

Klun, J. A. 1968. Isolation of a sex pheromone of the European corn borer. J. Econ. Entomol. 61: 484-487.

Koziel, M. G., G. L. Beland, C. Bowman, N. B. Carozzi, R. Crenshaw, L. Crossland, J. Dawson, N. Desai, M. Hill, S. Kadwell, et al. 1993. Field performance of elite transgenic maize plants expressing an insecticidal protein derived from Bacillus thuringiensis. Bio/Technology 11: $194-200$.

Lewis, L. C., and R. E. Lynch. 1969. Rearing the European corn borer, Ostrinia nubilalis (Hübner), on diets containing corn leaf and wheat germ. Iowa State J. Sci. 44: $9-14$.

Mason, C. E., M. E. Rice, D. D. Calvin, J. W. Van Duyn, W. B. Showers, W. D. Hutchison, J. F. Witkowski, R. A. Higgins, D. W. Onstad, and G. P. Dively. 1996. European corn borer: ecology and management. North Central Regional Extension Publ. 327. Iowa State University, Ames, IA.

McNeil, J. N., M. Cusson, J. Delisle, I. Orchard, and S. S. Tobe. 1995. Physiological integration of migration in Lepidoptera, pp. 279-302. In V. A. Drake and A. G. Gatehouse [eds.], Insect migration: tracking resources through space and time. Cambridge University Press, Cambridge, United Kingdom.

Ostlie, K. R., G. L. Hein, L. G. Higley, L. V. Kaster, and W. B. Showers. 1984. European corn borer (Lepidoptera: Pyralidae) development, larval survival, and adult vigor on meridic diets containing marker dyes. J. Econ. Entomol. 77: 118-120.

Ott, R. L., and M. Longnecker. 2001. An introduction to statistical methods and data analysis, 5th ed. Duxbury, Pacific Grove, CA.

Pilcher, C. D., M. E. Rice, R. A. Higgins, K. L. Steffey, R. L. Hellmich, J. Witkowski, D. Calvin, K. R. Ostlie, and M. Gray. 2002. Biotechnology and the European corn borer: measuring historical farmer perceptions and adoption of transgenic Bt corn as a pest management strategy. J. Econ. Entomol. 95: 878-892.

Raun, E. S. 1961. Elimination of microsporidiosis in laboratory reared European corn borer by use of heat. J. Insect Pathol. 3: 446-448.

Reardon, B. J., D. V. Sumerford, and T. W. Sappington. 2006. Dispersal of newly eclosed European corn borer (Lepidoptera: Crambidae) adults from corn into small-grain aggregation plots. J. Econ. Entomol. 99: 1641-1650.

Royer, L., and J. N. McNeil. 1993. Male investment in the European corn borer, Ostrinia nubilalis (Lepidoptera: Pyralidae): impact on female longevity and reproductive performance. Funct. Ecol. 7: 209-215.

Qureshi, J. A., L. L. Buschman, J. E. Throne, and S. B. Ramaswamy. 2005. Adult dispersal of Ostrinia nubilalis Hübner (Lepidoptera: Crambidae) and its implications for resistance management in Bt-maize. J. Appl. Entomol. 129: 281-292.

Sappington, T. W. 2005. First-flight Adult European corn borer (Lepidoptera: Crambidae) distribution in roadside vegetation relative to cropping patterns and crop phenology. Environ. Entomol. 34: 1541-1548.

Sappington, T. W., and W. B. Showers. 1983a. Adult European corn borer (Lepidoptera: Pyralidae) flight activity in and away from aggregation sites. Environ. Entomol. 12: $1154-1158$

Sappington, T. W., and W. B. Showers. 1983b. Comparison of three sampling methods for monitoring adult European corn borer population trends. J. Econ. Entomol. 76: 12911297. 
SAS Institute. 2001. SAS user's guide: statistics, version 8.2. SAS Institute, Cary, NC.

Showers, W. B., G. L. Reed, and H. Oloumi-Sadeghi. 1974. Mating studies of female European corn borer: relationship between deposition of egg masses on corn and captures in light traps. J. Econ. Entomol. 67: 616-619.

Showers, W. B., G. L. Reed, J. F. Robinson, and M. B. DeRozari. 1976. Flight and sexual activity of the European corn borer. Environ. Entomol. 5: 1099-1104.

Showers, W. B., E. C. Berry, and L. Von Kaster. 1980. Management of 2nd-generation European corn borer by controlling moths outside the cornfield. J. Econ. Entomol. 73: $88-91$.
Showers, W. B., R. L. Hellmich, M. E. Derrick-Robinson, and W. H. Hendrix, III. 2001. Aggregation and dispersal behavior of marked and released European corn borer (Lepidoptera: Crambidae) adults. Environ. Entomol. 30: $700-710$.

XiangQuan, K., D. D. Calvin, M. C. Knapp, and F. L. Poston. 2004. Female European corn borer (Lepidoptera: Crambidae) ovarian development stages: their association with oviposition and use in a classification system. J. Econ. Entomol. 97: 828-835.

Received 27 December 2006; accepted 10 April 2007. 